\title{
Is vaginal discharge a natural or pathological problem in pregnant women associated with adverse pregnancy outcomes?: A cross-sectional study
}

\author{
Meharunnissa Khaskheli ${ }^{1}$, Shahla Baloch ${ }^{1}$, Aneela Sheeba Baloch ${ }^{1}$, and Syed Ghulam \\ Sarwar Shah ${ }^{2}$ \\ ${ }^{1}$ Liaquat University of Medical and Health Sciences \\ ${ }^{2}$ Oxford University Hospitals NHS Foundation Trust
}

June 8, 2020

\begin{abstract}
Objective: To differentiate between normal and pathological vaginal discharge (PVD) in pregnant women and to identify causes of and adverse pregnancy outcomes associated with PVD. Design: A cross-sectional study. Setting: Outpatient antenatal clinics. Population / Sample: Pregnant women, Convenience sample (N=85). Methods: Data were collected through history, clinical examination and laboratory investigations. Data analysed by frequencies, descriptive statistics and Chi-Squared tests. Main outcome measures: Vaginal discharge (VD), age, gestation, parity and adverse pregnancy outcomes. Results: Women's mean age was $27.4( \pm 4.67)$ years. Majority of women were 26-31 years old (40\%), 28-35 weeks pregnant (34\%) and primigravida (41\%). Of $89 \%(n=76)$ women with VD, $32 \%(n=24)$ had normal VD and $68 \%(n=52)$ PVD. Normal VD was watery $(100 \%)$ and odourless (96\%) while PVD was yellowish curd like (33\%) and foul smelling (52\%). PVD was significantly associated with bacterial vaginosis $(\mathrm{P}<0.0001)$, candidiasis $(\mathrm{P}=0.005)$ and trichomoniasis $(\mathrm{P}=0.018)$. A higher proportion of women with PVD reported irritation $(\mathrm{P}<0.0001)$, pain $(\mathrm{P}<0.0001)$, uterine contractions $(\mathrm{P}<0.0001)$, premature membrane rupture $(\mathrm{P}<0.0001)$, abortion $(\mathrm{P}<0.042)$, pre-term delivery $(\mathrm{P}<0.0001)$ and post-partum endometritis $(\mathrm{P}<0.0001)$. $\mathrm{PVD}$ was also associated with low birth weight $(\mathrm{P}<0.0001)$, low Apgar score at birth $(\mathrm{P}<0.0001)$, respiratory distress syndrome $(\mathrm{P}$ $<0.0001)$, intensive neonatal care hospitalisation $(\mathrm{P}=0.001)$ and early neonatal death $(\mathrm{P}=0.002)$. Conclusions: Vaginal discharge in pregnancy requires early investigation to avoid any adverse fetomaternal outcomes associated with pathological vaginal discharge.
\end{abstract}

\section{Introduction}

Vaginal discharge is a common gynaecological complaint among women during their reproductive life and especially during pregnancy. Women are usually unable to differentiate between normal and abnormal vaginal discharge. ${ }^{1}$ Normal vaginal discharge or leucorrhoea is thin, clear, or milky white fluid with mild odour. One of the earliest signs of pregnancy is vaginal discharge that increases in amount progressively and continues throughout the pregnancy. Changes in vaginal discharge can begin as early as one to two weeks after the conception and the discharge usually becomes more noticeable as pregnancy progresses and becomes heaviest near the end of pregnancy. In the last weeks of pregnancy, vaginal discharge contains thick mucus mixed with streaks of blood, called "show." This is an early sign of labour and should not be the cause for alarm. Proper diagnosis and appropriate management of vaginal discharge is based on the clinical examination and laboratory investigations. ${ }^{2}$ 
Pathological vaginal discharge commonly occurs due to organismal infections of vagina such as Bacterial vaginosis (BV), Trichomonas vaginalis (TV) and Vulvovaginal candidiasis (VVC), which is also known as "vaginal candidiasis" or "candidal vaginitis."

These infections may lead to vaginal dysbiosis (abnormal vaginal microbiota) during early stages of pregnancy which is commonly associated with adverse pregnancy outcomes ${ }^{3}$ such as pre-term birth. ${ }^{4}$ About a half of pregnant women with $v$ aginal discharge experience pruritus (itching), malodour (very unpleasant smell), dysuria (painful or difficult urination), and dyspareunia (difficult or painful sexual intercourse). ${ }^{5}$

Bacterial vaginosis (BV) is a common vaginal infection that is prevalent in 15-30\% pregnancies and its adverse pregnancy outcomes include preterm labour and delivery, premature rupture of membranes (PROM), amniotic fluid infections and postpartum endometritis. ${ }^{6,7}$ Vaginal Candidiasis (VC) is a common type of vaginal infection caused by overgrowth of Candida species, ${ }^{8}$ which are part of the lower genital tract flora present in healthy asymptomatic women. ${ }^{9} \mathrm{VC}$ is a gynaecologic disorder with a white vaginal discharge, vaginal pain, difficult or painful sexual intercourse, irritation and itching. The rate of $\mathrm{VC}$ is higher in women treated with broad spectrum antibiotics and women who are pregnant and/or diabetic and have HIV/AIDS. Candida albicans is the most common of vaginal Candida species followed by Candida glabrata that cause vaginal Candidiasis among pregnant women. ${ }^{10}$ Vaginal candidiasis may lead to pregnancy complications such as abortion, premature birth, low birth weight and other morbidities. ${ }^{6,8} \mathrm{BV}$, VVC and TV affect about $6 \%$ women. ${ }^{11}$ These infections are associated with vaginal discharge and particularly affect women of low socio-economic background and low literacy level. ${ }^{6,7}$ Abnormal vaginal discharge due to vaginal infections is also common during child bearing age. Because of socio-psychological impacts and adverse maternal and foetal outcomes vaginal discharge is an important public health issue, which needs further research especially in women of lower socio-income communities and those living in lower and middle income countries such as Pakistan where pregnant women have a higher prevalence of candidiasis ${ }^{12,13}$ and other bacterial infections. ${ }^{14}$

The objectives of this study were to differentiate between normal and pathological vaginal discharge in pregnant women and to identify common causes of and adverse pregnancy outcomes associated with pathological vaginal discharge.

\section{Methodology}

This cross-sectional study was conducted at an Obstetrics and Gynaecology unit of a University teaching hospital from 1 June 2018 to 31 May 2019. All women who came for routine antenatal check-up and had had complaint of vaginal discharge were invited to the study. We were able to recruit a convenience sample of 85 women over the 12 month period of the study. All pregnant women with threatened abortion, cervical incompetence, placental abnormalities, history of sexually transmitted disease (STI) and treatment at STI clinics were excluded from the study. All women were recruited to the study after taking their informed written consent.

Data were collected by taking detailed history and thorough clinical examination. Three samples of vaginal discharge were also taken for laboratory investigation. ${ }^{15}$ The first sample was stored in a vial with $95 \%$ alcohol for cytological examination; the second sample was utilised in the amine test; and the third sample was taken with a cotton swab, which was immersed in normal saline $\left(1 \mathrm{ml}\right.$, in sterile glass) for direct examination. ${ }^{16}$. The samples were sent to our pathological diagnostic research centre for examination and report. For candidiasis and trichomoniasis, direct microscopically examination was taken as the gold standard for seeing hyphae and flagellate. ${ }^{17}$ For diagnosis of bacterial vaginosis, the Amsel criteria ${ }^{18}$ were taken as the gold standard. ${ }^{19}$ The diagnosis of bacterial vaginosis was confirmed by the presence of three of following four conditions: vaginal discharge, vaginal $\mathrm{pH}>4.5$, positive result in the amine test and presence of clue cells on microscopy. ${ }^{18}$

The data were collected on different variables i.e. age, parity, gestational period, symptoms and their duration, amount and colour of vaginal discharge with concomitant complaints such as irritation, smell, pain as discomfort and true onset of labour pains. 
All continuous variables were analysed with simple percentages and frequency, mean values with standard deviation while categorical variables were analysed with Chi Square tests. P-Value [?]0.05 was considered for statistical significant. There were no missing values. Data were analysed in SPSS, version 23 for Windows. ${ }^{20}$

\section{Results}

\section{Demographic and gestation characteristics}

In total, 85 pregnant women took part in this study. Women's mean age was $27.40( \pm 4.67)$ years and the youngest and the eldest women were 20 and 37 years old respectively. Majority of women were 26-31 years of age (40\%), 28-35 weeks pregnant (34\%) and primigravida (41\%) (Table 1).

$<$ Please insert Table 1 here $>$

\section{Physical characteristics and laboratory examination of vaginal discharge}

Vaginal discharge was reported by $89 \%(\mathrm{n}=76)$ women. Of these women, $32 \%(\mathrm{n}=24)$ had normal (physiological) discharge and $68 \%(\mathrm{n}=52)$ had pathological discharge. Physiological vaginal discharge was watery coloured discharge $(n=24,100 \%)$ and it was a slight stain in quantity $(n=22,92 \%)$ and odourless $(n=23,96 \%)$ while pathological discharge was mostly yellowish curd $(\mathrm{n}=17,33 \%)$, soaking clothes in quantity $(\mathrm{n}=35,67 \%)$ and foul smelling $(\mathrm{n}=27,52 \%)$ (Table 2$)$.

Laboratory examination of vaginal discharge samples confirmed vaginal infections which included bacterial vaginosis $(\mathrm{n}=21,24.7 \%)$, candidiasis $(\mathrm{n}=18,21.2 \%)$, and trichomoniasis $(\mathrm{n}=15,17.6 \%)$. There was statistically significant association between pathological vaginal discharge and bacterial vaginosis $(\mathrm{P}<0.0001)$, candidiasis $(\mathrm{P}=0.005)$ and trichomoniasis $(\mathrm{P}=0.018)$ (Table 2).

$<$ Please insert Table 2 here $>$

\section{Vaginal discharge and adverse maternal, pregnancy and neonatal outcomes}

A higher proportion of pregnant women with pathological vaginal discharge reported statistically significant adverse maternal and neonatal outcomes. The significant adverse maternal outcomes associated with pathological discharge were irritation $(\mathrm{P}<0.0001)$, pain $(\mathrm{P}<0.0001)$, uterine contractions $(\mathrm{P}<0.0001)$, premature membrane rupture $(\mathrm{P}<0.0001)$, abortion $(\mathrm{P}<0.042)$, pre-term delivery $(\mathrm{P}<0.0001)$ and postpartum endometritis $(\mathrm{P}<0.0001)$ (Table 3$)$. The adverse neonatal outcomes significantly associated with pathological vaginal discharge were low birth weight $(\mathrm{P}<0.0001)$, low Apgar score at birth $(\mathrm{P}<0.0001)$, respiratory distress syndrome $(\mathrm{P}<0.0001)$, intensive neonatal care hospitalisation $(\mathrm{P}=0.001)$ and early neonatal death $(\mathrm{P}=0.002)$ (Table 3).

$<$ Please insert Table 3 here $>$

\section{Discussion:}

\section{Normal vs pathological vaginal discharge}

Vaginal discharge is common during pregnancy and it is important to differentiate between natural (physiological) discharge and pathological discharge. In this study, we characterised normal (physiological) and pathological vaginal discharge and identified risk factors and adverse maternal and neonatal outcomes associated with pathological vaginal discharge. We found normal pathological vaginal discharge in three and seven of ten pregnant women. The former type of vaginal discharge was not a serious nuisance in terms of 
colour, quantity and odour while the later type of vaginal discharge was a serious issue not only in regards to these parameters ${ }^{5}$ but also in terms of associated adverse impacts on the mother, pregnancy and neonates.

\section{Common causes of pathological vaginal discharge}

Out findings revealed statistically significant associations between pathological vaginal discharge and common vaginal infections i.e. bacterial vaginosis, vaginal candidiasis and trichomoniasis vaginalis, ${ }^{21,22}$ which are commonly found in pregnant women with low education, underprivileged social and economic status and poor hygiene. ${ }^{6}$ Most of women participants of our study were recruited during antenatal appointments in the outpatient obstetrics and gynaecology clinics, which are mostly attended by poor families in Pakistan. In addition, the literacy in female is also low $(52 \%)$ in the country, which is even lower in rural areas $(40.5 \%){ }^{23}$ These factors may have contributed in the higher prevalence of pathological vaginal discharge in our sample. Thus, our study shows that pathogenic organisms such as BV, VVC and TV are the major risk factors of pathological vaginal discharge in pregnant women. ${ }^{24}$ Thus, these infections need proper investigation and appropriate treatment.

We did not find any statistically significant differences in the preponderance of normal and pathological vaginal discharge based on the women's age, gestation period and parity. ${ }^{25}$

Adverse maternal, pregnancy and neonatal outcomes associated with vaginal discharge

Our findings revealed statistically significant higher proportion of women with pathological vaginal discharge with adverse maternal, pregnancy and neonatal outcomes. The adverse maternal outcomes were irritation and pain and uterine contractions and post-partum endometritis and the adverse pregnancy outcomes were premature membrane rupture, abortion and pre-term delivery. ${ }^{26}$ The adverse neonatal outcomes significantly associated with pathological vaginal discharge were low birth weight, low Apgar score at birth, respiratory distress syndrome, intensive neonatal care hospitalisation and early neonatal death. Our findings thus provide empirical evidence that pathological vaginal discharge in pregnant women is a serious maternal c health issue, which needs through clinical examination, laboratory investigation and relevant medical treatment and appropriate advice to pregnant women. ${ }^{22}$ These approaches especially laboratory investigation for confirmation of infection and abnormal vaginal micro biota should be the main part of routine antenatal care practices in developing countries like Pakistan, because the management only on the basis of signs and symptoms will not give proper cure and there will be increased opportunities for taking unnecessary multi drug regimes. It is therefore imperative that pathological vaginal discharge is differentiated from normal vaginal discharge so that appropriate treatment for the particular type of pathogenic infections is prescribed to improve women's health and pregnancy outcomes, while the women with physiological vaginal discharge could be counselled, assured and advised for good personal hygiene habits and avoidance of unnecessary medication.

\section{Strengths and limitations}

This study contributes in the body of knowledge by providing empirical evidence on the prevalence of normal (physiological) and abnormal (pathological) vaginal discharge in pregnant women and a number of adverse maternal, pregnancy and neonatal outcomes associated with pathological vaginal discharge in pregnant women in low and middle income settings and countries like Pakistan.

However, our study has a few limitations, which include convenience sampling, and lack of data on participant's education level and economic and employment status. It may be pertinent to state that there are no universal, mandatory and systematic antenatal screening appointment programme and facilities in Pakistan. It is therefore up to the pregnant woman and her family to seek an antenatal check-up, which depends on their choice but mostly on their income level. Women from affording families and higher income mostly go to the private practitioners and hospitals for antenatal check-up while women of poor families and low income commonly visit outpatient antenatal clinics in government hospitals. We therefore used the convenience 
sample because it was the most suitable sampling methods ${ }^{12}$ in the setting this study was undertaken i.e. outpatient antenatal clinics. ${ }^{12,13}$

We could not get information on the participating women's education level and economic and employment status. However, most of patients including pregnant women who attend outpatient clinics in Pakistan belong to families who are mostly poor and have low level of education. In addition, our hospital serves patients from a waste catchment area of rural area where the majority of people are poor, less educated and involved in agriculture. ${ }^{23}$ Low literacy and low income along with unemployment could be risk factors of poor personnel hygiene often associated with vaginal infections in pregnant women. ${ }^{6,7}$ Because of these limitations, the generalisability of our findings might be limited.

\section{Conclusions}

Vaginal discharge is common during pregnancy and it is essential to differentiate between normal and abnormal vaginal discharge. Abnormal (pathological) vaginal discharge is more frequent and commonly due to vaginal infections such as bacterial vaginosis, candidiasis and trichomoniasis, which can be treated with appropriate medicines and avoided through education and advice from improving personal hygiene. In addition, there is a need for universal antenatal screening and care services, especially in rural areas, in Pakistan.

Acknowledgements Authors wish to thank all participants for taking part in this study.

Ethics approval This study was approved by the Research Ethics Committee at Liaquat University of Medical and Health Sciences, Jamshoro, Pakistan (Ref. No. LUMHS/REC/768, Date: 25/05/2018). All participants provided informed consent.

Author contributions MK : study planning and conduct, data analysis and manuscript drafting; SB : study planning and manuscript review; AB : Data collection and manuscript review;SS : Data analysis and manuscript review, redrafting, editing and updating.

Funding of study None.

Competing Interests Authors declared no conflict of interest.

Author approval All authors have read and approved final version of the manuscript.

\section{References:}

1. Ilankoon IMPS, Goonewardena CSE, Fernandopulle R, Perera PPR. Women's understanding and cultural practices related to vaginal discharge: A qualitative study. Nurs Midwifery Stud. 2018;7(2):74-80.

2. Neal CM, Kus LH, Eckert LO, Peipert JF. Noncandidal vaginitis: a comprehensive approach to diagnosis and management. Am J Obstet Gynecol. 2020;222(2):114-22.

3. Margarita V, Fiori PL, Rappelli P. Impact of Symbiosis Between Trichomonas vaginalis and Mycoplasma hominis on Vaginal Dysbiosis: A Mini Review. Front Cell Infect Microbiol. 2020;10:179.

4. Peelen MJ, Luef BM, Lamont RF, de Milliano I, Jensen JS, Limpens J, et al. The influence of the vaginal microbiota on preterm birth: A systematic review and recommendations for a minimum dataset for future research. Placenta. 2019;79(30-39).

5. Reichman O, Gal M, Leibovici V, Samueloff A. Evaluation of Vaginal Complaints During Pregnancy: the Approach to Diagnosis. Curr Derm Rep. 2014;3(3):159-64. DOI: 10.1007/s13671-014-0083-0

6. Abdul-Aziz M, Mahdy MAK, Abdul-Ghani R, Alhilali NA, Al-Mujahed LKA, Alabsi SA, et al. Bacterial vaginosis, vulvovaginal candidiasis and trichomonal vaginitis among reproductive-aged women seeking primary healthcare in Sana'a city, Yemen. BMC Infect Dis. 2019;19(1):879. DOI:10.1186/s12879-019-4549-3 
7. Dilrukshi GN, Kottahachchi J, Dissanayake DMBT, Pathiraja RP, Karunasingha J, Sampath MKA, et al. Group B Streptococcus colonisation and their antimicrobial susceptibility among pregnant women attending antenatal clinics in tertiary care hospitals in the Western Province of Sri Lanka. J Obstet Gynaecol. 202016 (Published online:1-6. DOI:10.1080/01443615.2020.1716313

8. Vieira-Baptista P, Bornstein J. Candidiasis, bacterial vaginosis, trichomoniasis and other vaginal conditions affecting the vulva. In: Bornstein J, editor. Vulvar Disease. Cham: Springer; 2019. p. 167-205. DOI: 10.1007/978-3-319-61621-6_24

9. Bradford LL, Ravel J. The vaginal mycobiome: A contemporary perspective on fungi in women's health and diseases. Virulence. 2017;8(3):342-51. DOI:10.1080/21505594.2016.1237332

10. Nelson M, Wanjiru W, Margaret MW. Prevalence of vaginal candidiasis and determination of the occurrence of Candida species in pregnant women attending the antenatal clinic of Thika District Hospital, Kenya. Open J Med Microbiol. 2013;3(4):41031.

11. Tellapragada C, Eshwara VK, Bhat P, Kamath A, Aletty S, Mukhopadhyay C. Screening of vulvovaginal infections during pregnancy in resource constrained settings: Implications on preterm delivery. J Infect Public Health. 2017;10(4):431-7.

12. Parveen N, Munir AA, Din I, Majeed R. Frequency of vaginal candidiasis in pregnant women attending routine antenatal clinic. J Coll Physicians Surg Pak. 2008;18(3):154-7.

13. Saleem B, Jeelani SF, Sher SJ. Frequency of vaginal candidiasis in symptomatic pregnant women attending routine antenatal clinic. Pak J Med Sci. 2016;10(3):770-2.

14. Munir SI, Waheed K, Khanum A, Iqbal R, Eusaph AZ, Hanif A. Frequency of group B streptococci in pregnant women in a tertiary care hospital. J Coll Physicians Surg Pak. 2016;26(1):27-30.

15. Van Der Pol B. Clinical and Laboratory Testing for Trichomonas vaginalis Infection. Kraft CS, editor. J Clin Microbiol. 2016;54(1):7-12.

16. Kelly KG. Chapter 179. Tests on Vaginal Discharge. In: Walker HK, Hall WD, Hurst JW, editors. Clinical Methods: The History, Physical, and Laboratory Examinations. 3rd ed. Boston: Butterworths; 1990. pp.833835.

17. Harstall C, Corabian P. Diagnostic tests for vaginosis/vaginitis [Internet]. Edmonton, Alberta: Alberta Heritage Foundation for Medical Research; 1998. Available from: https://www.ihe.ca/download/diagnostic_tests_for_vaginosis_vaginitis.pdf

18. Amsel R, Totten PA, Spiegel CA, Chen KCS, Eschenbach D, Holmes KK. Nonspecific vaginitis: Diagnostic criteria and microbial and epidemiologic associations. Am J Med. 1983;74(1):14-22. DOI:10.1016/00029343(83)91112-9

19. Mohammadzadeh F, Dolatian M, Jorjani M, Alavi Majd H. Diagnostic value of Amsel's clinical criteria for diagnosis of bacterial vaginosis. Glob J Health Sci. 2014;7(3):8-14. DOI: 10.5539/gjhs.v7n3p8

20. IBM Corp. IBM SPSS Statistics for Windows, Version 23.0. Armonk, NY: IBM Corp.; 2015.

21. Kalia N, Singh J, Kaur M. Microbiota in vaginal health and pathogenesis of recurrent vulvovaginal infections: a critical review. Ann Clin Microbiol Antimicrob. 2020;19(1):5 (2020). DOI:10.1186/s12941-020$0347-4$

22. Obiero J, Rulisa S, Ogongo P, Wiysonge CS. Nifuratel-Nystatin combination for the treatment of mixed infections of bacterial vaginosis, vulvovaginal candidiasis, and trichomonal vaginitis. Cochrane Database Syst Rev. 2018;(4):CD013012.

23. Government of Pakistan. Pakistan Economc Survey 2018-19. Islamabad: Ministry of Finance; 2019. 
24. Nnadi DC, Singh S. The prevalence of genital Candida species among pregnant women attending antenatal clinic in a tertiary health center in North-west Nigeria. Sahel Med J. 2017;20(1):33-7.

25. Abdelaziz ZA, Ibrahim ME, Bilal NE, Hamid ME. Vaginal infections among pregnant women at Omdurman Maternity Hospital in Khartoum, Sudan. J Infect Dev Ctries. 2014;8(4):490-7.

26. Işik G, Demirezen Ş, Dönmez HG, Beksaç MS. Bacterial vaginosis in association with spontaneous abortion and recurrent pregnancy losses. J Cytol. 2016;33(3):135-40.

Table 1 Demographic and gestational characteristics $(\mathrm{N}=85)$

\begin{tabular}{|c|c|c|c|c|c|c|c|}
\hline & Number & Percentage & Mean (standard deviation) & & Vaginal discharge & & \\
\hline & & & & No & Yes & & $P-v c$ \\
\hline & & & & & Pathological & Physiological & \\
\hline \multicolumn{8}{|l|}{ Age } \\
\hline $20-25$ years & 32 & 37.7 & & 3 & 17 & 12 & \\
\hline 26-31 years & 34 & 40.0 & $27.4(4.67)$ & 5 & 24 & 5 & $?>?$ \\
\hline 32 years & 19 & 22.3 & & 1 & 11 & 7 & \\
\hline Gestational period & & & & & & & 0.12 \\
\hline 8-14 weeks & 15 & 17.6 & & 2 & 5 & 8 & \\
\hline 15-21 weeks & 17 & 20 & & 3 & 9 & 5 & \\
\hline $22-27$ weeks & 24 & 28.2 & & 3 & 16 & 5 & \\
\hline 28-35 weeks & 29 & 34.1 & & 1 & 22 & 6 & \\
\hline Parity & & & & & & & 0.5 \\
\hline Primigravida & 35 & 41.2 & & 4 & 20 & 11 & \\
\hline Para 2-4 & 34 & 40.0 & & 5 & 21 & 8 & \\
\hline Para 5 and above & 16 & 18.8 & & 0 & 11 & 5 & \\
\hline
\end{tabular}

Table 2 Vaginal discharge - physical characteristics and causative pathogenic organisms $(\mathrm{N}=85)$

\begin{tabular}{|c|c|c|c|c|c|c|}
\hline & Number & Percentage & & Vaginal discharge & Vaginal discharge & \\
\hline & & & No & Yes & Yes & P-value \\
\hline & & & & Pathological & Physiological & \\
\hline \multicolumn{7}{|c|}{ Physical characteristics } \\
\hline No & 9 & 10.6 & & & & \\
\hline Yes & 76 & 89.4 & & & & \\
\hline Pathological & 52 & 61.2 & & & & \\
\hline Physiological & 24 & 28.2 & & & & \\
\hline \multicolumn{7}{|l|}{ Colour } \\
\hline Watery & 34 & 40.0 & 0 & 10 & 24 & $<0.0001$ \\
\hline Yellowish curd like & 17 & 20.0 & 0 & 17 & 0 & \\
\hline Frothy & 12 & 14.1 & 0 & 12 & 0 & \\
\hline Muddy & 13 & 15.3 & 0 & 13 & 0 & \\
\hline No discharge & 9 & 10.6 & 9 & 0 & 0 & \\
\hline \multicolumn{7}{|l|}{ Quantity } \\
\hline Slight stain & 37 & 43.5 & 0 & 6 & 22 & $<0.0001$ \\
\hline Soaking clothes & 36 & 42.4 & 0 & 35 & 1 & \\
\hline Copious in amount & 12 & 14.1 & 0 & 11 & 1 & \\
\hline No discharge & 9 & 10.6 & 9 & 0 & 0 & \\
\hline \multicolumn{7}{|l|}{ Odour } \\
\hline Odourless & 43 & 50.6 & 0 & 11 & 23 & $<0.0001$ \\
\hline
\end{tabular}




\begin{tabular}{|c|c|c|c|c|c|c|}
\hline & Number & Percentage & & Vaginal discharge & Vaginal discharge & \\
\hline Fishy odour & 14 & 16.5 & 0 & 14 & 0 & \\
\hline Foul smelling & 28 & 32.9 & 0 & 27 & 1 & \\
\hline No discharge & 9 & 10.6 & 9 & 0 & 0 & \\
\hline \multicolumn{7}{|c|}{ Causative pathogenic organisms } \\
\hline Candidiasis & & & & & & 0.005 \\
\hline No & 67 & 78.8 & 9 & 35 & 23 & \\
\hline Yes & 18 & 21.2 & 0 & 17 & 1 & \\
\hline \multicolumn{7}{|c|}{ Trichomoniasis } \\
\hline No & 70 & 82.4 & 9 & 38 & 23 & 0.018 \\
\hline Yes & 15 & 17.6 & 0 & 14 & 1 & \\
\hline \multicolumn{7}{|c|}{ Bacterial Vaginosis } \\
\hline No & 64 & 75.3 & 9 & 31 & 24 & $<0.0001$ \\
\hline Yes & 21 & 24.7 & 0 & 21 & 0 & \\
\hline
\end{tabular}

Table 3 Adverse maternal, pregnancy and neonatal outcomes associated with pathological vaginal discharge $(\mathrm{N}=85)$

\begin{tabular}{|c|c|c|c|c|c|c|}
\hline & Number & Percentage & & & Vaginal Discharge & Vaginal Dis \\
\hline & & & No & Pathological & Pathological & Physiologic \\
\hline \multicolumn{7}{|c|}{ Maternal and pregnancy outcomes } \\
\hline \multicolumn{7}{|c|}{ Associated Irritation } \\
\hline No & 54 & 63.5 & 9 & 23 & 23 & 22 \\
\hline Yes & 31 & 36.5 & 0 & 29 & 29 & 2 \\
\hline \multicolumn{7}{|c|}{ Associated Pain } \\
\hline No & 29 & 34.1 & 7 & 3 & 3 & 19 \\
\hline Yes & 56 & 65.9 & 2 & 49 & 49 & 5 \\
\hline \multicolumn{7}{|c|}{ Uterine contraction } \\
\hline No & 54 & 63.5 & 9 & 22 & 22 & 23 \\
\hline Yes & 31 & 36.5 & 0 & 29 & 29 & 1 \\
\hline \multicolumn{7}{|c|}{ Premature rupture of membranes } \\
\hline No & 56 & 65.9 & 9 & 24 & 24 & 23 \\
\hline Yes & 29 & 34.1 & 0 & 28 & 28 & 1 \\
\hline \multicolumn{7}{|c|}{ Abortion } \\
\hline No & 72 & 84.7 & 9 & 40 & 40 & 23 \\
\hline Yes & 13 & 15.3 & 0 & 12 & 12 & 1 \\
\hline \multicolumn{7}{|c|}{ Preterm delivery } \\
\hline No & 61 & 71.8 & 9 & 28 & 28 & 24 \\
\hline Yes & 24 & 28.2 & 0 & 24 & 24 & 0 \\
\hline \multicolumn{7}{|c|}{ Post partem endometritis } \\
\hline No & 66 & 77.7 & 9 & 33 & 33 & 24 \\
\hline Yes & 19 & 22.3 & 0 & 19 & 19 & 0 \\
\hline \multicolumn{7}{|c|}{ Fever } \\
\hline No & 73 & 85.9 & 9 & 41 & 41 & 23 \\
\hline Yes & 12 & 14.1 & 0 & 11 & 11 & 1 \\
\hline \multicolumn{7}{|c|}{ Neonatal outcomes } \\
\hline \multicolumn{7}{|c|}{ Low birth weight } \\
\hline No & 61 & 71.8 & 9 & 28 & 28 & 24 \\
\hline Yes & 24 & 28.2 & 0 & 24 & 24 & 0 \\
\hline
\end{tabular}




\begin{tabular}{lllllll}
\hline & Number & Percentage & & & Vaginal Discharge & Vaginal Dis \\
\hline No & 63 & 74.1 & 9 & 30 & 30 & 24 \\
Yes & 22 & 25.9 & 0 & 22 & 22 & 0 \\
Respiratory distress syndrome & & & & & \\
No & 64 & 75.3 & 9 & 31 & 31 & 24 \\
Yes & 21 & 24.7 & 0 & 21 & 21 & 23 \\
Intensive neonatal care hospitalisation & & & & & \\
No & 64 & 75.3 & 9 & 32 & 32 & 24 \\
Yes & 21 & 24.7 & 0 & 20 & 20 & \\
Early neonatal death & & & & & \\
No & 69 & 81.2 & 9 & 36 & 36 & 16 \\
Yes & 16 & 18.8 & 0 & 16 & & \\
\hline
\end{tabular}

